\title{
Enhancing Confidence, Competence, and Connection in Engineering
}

\author{
Andrew Roncin, P. Eng. \\ Instructor, Electrical/Electronic Engineering Technology \\ Red River College \\ aroncin@rrc.mb.ca
}

\begin{abstract}
In December of 2010, a pilot study into the perceptions of engineering instructors was done. From the interviews with engineering faculty, an overview of the current practices and attitudes in engineering were developed. One of the problems highlighted in this work, was that instructors felt pressured by class size, time, and amount of content to use lectures while teaching to teach. However, this may not be the methodology for encouraging student learning.

The benefit of this research is that it provides a good background for understanding teaching environment facing current engineering instructors. So that when combined with the works on teaching engineering and education, we can suggest methods of teaching that are relevant and realistic to engineering classrooms.

In short, this paper will examines suggestions for enhancing the confidence, competence, and connection of engineering students
\end{abstract}

\section{Introduction}

In his article "Do engineering faculty know what's broken" Sanjay Goel [1] of Jayee Institute of Information Technology in India highlights how much engineering instructors use lecturing vs how effective students found the technique. His key findings show a 0.99 correlation between the least effective techniques as viewed by students being the most often used. Rather than listen to lectures, his paper states that students want to creatively engage and discover the knowledge for themselves.

The simple question is, if this seems intuitively obvious, why do we continue to use lectures as our dominant form of teaching? [2] And a more involved question becomes, how can we improve it?

"The aim of education, then, is not to guide learners toward completion, but to provide them experiences that challenge and enlarge their understandings.” [3]

Discussing these matters with engineering faculty and current literature on teaching, we see that improving education comes from more actively engaging the minds and creativity of our students. Getting students to think about what they are learning and how they can apply it is critical to our success as teachers.

"[T] hese are still students, we have to develop, we have to bring them up, to a level where people hire them out, that the taxpayer wants." (Beta)

\section{Research Context}

During the winter or 2010, I interviewed several engineering educators as part of a pilot project on Engineering Education in Canada. The projects aim was to identify what was happening in engineering classrooms in order to understand the challenges faced by engineering and technology instructors.

The motivation for this comes from two aspects. First, by 2014, engineering schools are expected to incorporate skills like design, teamwork, communication and leadership on top of technical excellence in the classroom.[4] Second, an article by Sanjay Goel "Do engineering faculty know what's broken" [1]. Which illustrated how the most used teaching technique - lecturing was seen as the least useful technique in the mind of students. A statement whose depth can be seen in the works of Felder [5][6], Krathwohl [7], Davis [3], and Sheppard [8].

Over the course of four interviews with engineering faculty, the conflict between the constraints of teaching and the desire to produce excellent engineers became 
apparent. The theme competence, competence, and connection came from the idea that when students are engaged, motivated, and involved - they perform better and develop a better understanding of the material. [9]

\section{Methodology}

This project was done as a pilot study to qualitatively understand Canadian engineering professor and engineering technology instructor's attitudes towards teaching engineering.

Two institutions were solicited, from which four faculty (Alpha, Beta, Gamma, and Delta) were randomly selected. Each participant was interviewed for one hour using a semi-structured interview with five questions.

Once transcription was complete, each participant was asked to review their transcript for accuracy. In accordance with human ethics approval and ensure anonymity, all identifying comments were removed from the transcript and not used in data analysis.

Coding of the data was done heuristically using grounded theory. This resulted in 90 codes, where the key responses were in the areas of methodology, engagement and ownership of knowledge.

\subsection{Limitations}

This project has three major limitations, researcher positioning, sample size and focus.

First, as a college instructor and professional engineer, I have a bias as to what qualifies as good instruction and what is expected of engineering and engineering technology graduates. This bias like many other faculty is that students from engineering and technology disciplines should be very technically competent and independent problem solvers when they are finish their education. And that good instruction facilitates the students becoming employable members of society.

The second limitation is sample size. As a pilot project, two institutions were approached and because of time constraints, only one institution was able to participate. From which, four faculty were interviewed. Each of these faculty members had a minimum of three years teaching experience, taught higher year courses and had very different areas of technical expertise within engineering.

The third limitation is focus. The original questions for this project were designed to understand the motivations and teaching environment of instructors in the classroom. Each participant was asked about how long they had been teaching, their purpose in the classroom, and their expectations technical and behavioural of students. The results of confidence, competence, and connection are inferred from their responses and current literature on engineering education.

\section{Confidence, Competence, Connection}

\subsection{The challenge}

One of the biggest challenges we face, is that our students expect a more interactive environment. They expect their education to engage them.

"It's much harder now, to engage them and hold their attention. Because the expectation is that they should be entertained as much as they should be learning." (Beta)

Even if you have a bright high school student coming into your classroom. Unless you engage them, truly engage them, 10, 15 minutes into the lecture, their gone." (Beta)

However, when they are finished, industry expects our graduates to be problem solvers and effective communicators. [10][11][12][13]

"I teach engineering. With math in it and so on. But I tell them, I said, when you go out. Ah, nobody will interview you by giving you a problem to sit and they say to do this problem and give you a math problem.... The first thing they ask [is] they have a problem and they want to hear the solution that you have, that's all." (Delta)

Encouragingly all four of the participants strongly believed in their role of creating professional engineers. Depending on their specialty, this took different forms, but each wanted their students to be technically competent and able to solve problems.

\subsection{Confidence}

Confidence is our student's ability to tackle new problems, to deal with incomplete information, and "go beyond 'plug and chug'"'[14], and deal with the unknown. Confidence is about being able to create devices that have never been done before. Our graduates need to be confident in their abilities and able to accept the engineering opportunities they encounter.

"Yeah, that's the theory or knowledge, you learn the knowledge that's the factual thing, right and then they have to turn that knowledge into their own and they can actually use it. to solve the problem. not just something memorized." (Alpha)

The most important thing is you eliminate [the] fear of getting these responsibilities... self confidence in the field... is very important." (Gamma)

\subsection{Questions about Confidence}

“[In industry, you're expected to] provide solutions and problem solving skills. Meaning, I give you a 
problem, I don't have the coefficient that the prof is going to give you in a chart. I don't have the equations. You go find them. You go tell me what they are... You make assumptions. And many students freeze. They freeze because there is twenty unknowns and two known's." (Beta)

So why does this happen? Perhaps the students need more opportunities to work with the unknown, to engage in design, and put their thoughts into a form that a client will want. Perhaps, the problem is that although we are creating graduates who are technically qualified to be engineers, perhaps they need to see the complexities of real engineering work. [12][11] Unlike the technical aspects of engineering, confidence comes from dealing with the unknown.

\subsection{Building Confidence}

"We cannot teach them everything. With all the materials that is required in industry. But I [want them to] get confidence, that is, that they have seen it in real life, they will say, yes I can do it." (Gamma)

If we are going to build the confidence of our students, we need to give them more opportunities to connect theory and reality, to engage in design and to deal with the problems of incomplete information. They need to be able to connect the formulas and theories they are learning back to the real world. [6]

\subsubsection{Using the lab first}

In Alpha's course, connecting the theory and practice is very important. Typically, he will run a lab, and the next lecture, lead a student discussion on what they observed. Sketching their observations on the board, describing how beams break, and relating the concepts of stress and strain to their personal experience. By doing this, Alpha is building their confidence that what they are learning has value, that they can measure the unknown, and that they can connect it back to the theory they are learning in class.

"[F]or any engineering courses, you know, it's always nice to have some hands on stuff and relate the theory to... the stuff in the daily life. I think that's what we try to do in the problem of breaking the concrete... people see it and they just don't know why." (Alpha)

\subsubsection{Getting them to think about it}

An alternative method for helping students build confidence may be as simple as getting them actively thinking about the problems in class. Ask each student to summarize what is going on in class in their own words. Have them work in pairs (TAPPS) or write for three to five minutes on such questions as: [6][15]

1. Where could you apply this concept in practice?

2. Draw a flowchart of this process.
3. If your friend missed class, how could you summarize this for him?

By challenging students to reflect on what they are seeing, hearing, and learning, we are encouraging them to become confident in their knowledge. To take what they know, express it, and become confident with it.

By giving them opportunities to connect theory and reality, to engage in design, we allow them to see themselves as capable people.

By having them deal with incomplete information or real world measurements, we prepare them to confidently deal with uncertainty.

By challenging students to question what they know and forcing them to deal with incomplete information, we will build their confidence. Confidence to make assumptions, deal with the unknown and create solutions.

\subsection{Competence}

Like confidence, competence in engineering is about being able to deal with the unknown. It's about more than just technical knowledge and passing the exam. It's about being able to make assumptions, define the limits problems, and create a solution that works. [16] What makes engineering unique, is the implicit assumption that everything we work on, could be built in the real world. [17]

"If the beam breaks, then everybody can observe, yeah the beam breaks, like that. Well, the next question is why, how? Right, how that's actually going to relate to eventually, your design, if you're going to build, design a beam, then you understand what would happen if you put too much load on it. you know, and how do you design a beam to avoid problem." (Alpha)

The challenge with competence, is that it goes well beyond just technical skill. It also requires knowledge of standards, a breadth of engineering knowledge, and the ability to work in a business environment. [11][10]

"Remarkably few engineering graduates are actually practicing what would be remotely recognisable as what they were being taught, or even connected with it." [11]

But satisfying all the needs of industry is virtually impossible. Because of the large amount of technical information required to do engineering, and industries emphasis on decision making and working with clients.

"Industry wants technically capable people which requires a lot of core teaching... While at the same time, they want them to [have] almost five years of experience. Well they can't. These are 22 year old graduates, they have had 0 real experience... But they have a point when they say that the engineers come out and they are not ready to, to function in a professional setting” (Beta) 


\subsection{Building Competence}

So the question is, what can we do to move towards a student who is technically literate and able to function in the business world.

"You have to also be able to interpret the results, put the into a language the client can understand...Giving the slope to the client means nothing. You gotta explain what the slope means. And how that impacts his bottom line." (Beta)

Students need to work on problems where they cannot look in the back of the book for an answer. And when they get those problems, learn to interpret what they are seeing.

"[O]ur assignments, exams, in the fourth/fifth year have to be open ended. They have to have many right solutions. They have to have, a lot of flexibility in how you do it. Not just use one formula. You might get there differently. Because that is what you're going to be doing in real life." (Beta)

But going beyond this, students need to engage in design throughout the program. Although the idea may be countered with, "they don't know enough", if we think about consulting engineering, are we given all the information we need up front? If we want to build self reliant, confident engineers, then perhaps we need to find ways to build student competitions and design challenges into more of our courses throughout the program.

An interesting examples of using design challenges in the curriculum is the VECTOR program at Ohio State. [18] Where they revised the electromagnetics curriculum around simulating and constructing a capacitive sensor and a patch antenna both used in the control of a remote control car.

\subsection{Connection}

Feeling connected in engineering means feeling that what you are learning is valuable to your future, that you are part of the group, and ultimately, thinking like an engineer.[9] [17]

\subsubsection{Understanding the Impact}

In order to build this, we need to let them know why they are studying this, what can they build with it. How it might impact their future.

"[O]ne of the things you have to do then, is alert them to the fact that what you are learning today has some to do with what you might be doing tomorrow... When [guest speakers] come back into the classroom and as a student you look at them, you have to then immediately put yourself into their shoes. And you can ask them your questions... [T]his sets up a nice dynamic between them seeing their future, I like that." (Beta)

\subsubsection{Making it Fun}

Beyond just letting students know why we the information is important. We need to make it fun and social. In Alpha's case, he does this by getting his students to measure real things, letting the students get their hands dirty, and encouraging them to take a personal interest in the experiments.

"I ask students, I said, you have an option, because we testing some bone, I said I am bringing in some... drumsticks but you have to dissect, you know the drumstick to get the bone sample from them. from the chicken leg....If you have got any other samples you're ... interested in testing, tell me, let me know and then we bring it in.

And one student actually brought in a whole bag of... pig bones. and they start to dissect the bones, and a couple of students were particularly interested in the strength of the kneecap....

In the real life. You want to find out what the strength of the bone you don't expect the somebody else [to give it to you]... in the real life... you got a drumstick.”(Alpha)

\subsubsection{Taking ownership}

Perhaps the most important aspect of connection comes from taking ownership of your work. If we look at student competitions, K-12 outreach, and our own practice. When we own the experience, our engagement, our connection goes through the roof.

We can use this idea to enhance the engagement of our students as well. Pose questions without a right or wrong answer. What is the role of an engineer in society? Where should infrastructure be built? How would you solve this design problem. If we step back from the theory and ask, what's interesting, what's controversial, what's the challenge. Than opportunities to help students connect can easily come to light.

\subsubsection{Becoming a professional}

Finally, for the students, being connected means perceiving themselves as engineers. Beta does this by challenging his students to think of themselves as professionals. To think about the image they are portraying to their classmates. The benefit, his students buy in and behave in a much more professional manner.

"We tell them, look around you. Every one of those classmates you have, right now, will probably eventually be your colleges, your bosses.... So, so professionalism starts now.... And I think once you do that, then the attitude can automatically change." (Beta) 


\section{Conclusion}

Enhancing the confidence, competence and connection of students is critical. As engineers, it's easy to focus on teaching the technical details. But along with that, we should be asking; how can the students own the experience. Will this help them become more confident in dealing with uncertainty? Will this help them become more competent both technically and in the workplace? And finally, will this help them see themselves as engineers?

\section{References}

[1] S. Goel, "Do Engineering Faculty know What's Broken?," The National Teaching \& Learning Forum, vol. 15, no. 2, pp. 1-6, Feb. 2006.

[2] P. Zundel and P. Deane. (2010, Dec.) University Affairs.

[Online]. http://www.universityaffairs.ca/

[3] B. Davis, D. Sumara, and L. Luce-kapler, Engaging Minds: Changing Teaching in Complex Times, 2nd ed. Routledge, 2007.

[4] Canadian Engineering Accreditation Board, "Accreditation Criteria and Procedures," Canadian Council of Professional Engineer, 2008.

[5] R. M. Felder, "DESIGNING TESTS TO MAXIMIZE LEARNING," Journal of Professional Issues in Engineering Education and Practice, vol. 128, no. 1, 2002, http://dx.doi.org/10.1061/(ASCE)10523928(2002)128:1(1), http://www4.ncsu.edu/unity/lockers/users/f/felder /public/Papers/TestingTips.htm.

[6] R. M. Felder, D. R. Woods, J. E. Stice, and A. Rugarcia, "The Future of Engineering Education II. Teaching Methods that Work," Chem. Engr. Education, vol. 34, no. 1, pp. 36-39, 2000.

[7] D. R. Krathwohl, "A Revision of Bloom's Taxonomy: An Overview," Thoery Into Practice, pp. 212-218, 2002, http://www.unco.edu/cetl/sir/stating_outcome/do cuments/Krathwohl.pdf.

[8] S. D. Sheppard, K. Macatangay, A. Colby, and W. Sullivan, Educating Engineers. San Francisco: Jossy-Bass, 2009, The Carnegie Foundation for the Advancement of Teaching.

[9] L. Vanasupa, J. Stolk, and R. J. Herter, "The Four-Domain Development Diagram: A Guide for Holistic Design of Effective Learning Experiences for the Twenty-first Century
Engineer," Journal of Engineering Education, vol. 98, no. 1, pp. 67-81, Jan. 2009.

[10] K. J. B. Anderson, S. S. Courter, T. NathansKelly, C. Nicometo, and T. McGlamery, "Understanding the current work and values of professional engineers: Implications for engineering education," in Proceedings of the American Society of Engineering Education, Austin, TX, 2009.

[11] The Royal Academy of Engineering, "Educating Engineers for the 21st Century: The Industry View," 2006.

[12] The Canadian Academy of Engineering, "Task Force on the Future of Engineering: A Framework for Discussion," Dec. 2005. [Online]. http://www.acad-enggen.ca/nouveau/caerptmdf62.pdf

[13] National Academy of Engineering,, The Engineer of 2020: VISIONS OF ENGINEERING IN THE NEW CENTURY. Washington, DC: National Academies Press, 2004, http://www.nap.edu.

[14] S. R. Turns, "What Motivates Your Teaching," Journal of STEM Education, vol. 11, no. 1\&2, pp. 5-16, Jan. 2010.

[15] L. J. Lucas, "Awake, Accountable, and Engaged," The National Teaching \& Learning Forum, vol. 19, no. 4, pp. 1-4, 2010.

[16] R. E. Mayer, "Rote Versus Meaningful Learning," Theory into Practice, vol. 41, no. 4, pp. 226-232, 2002, http://www.unco.edu/cetl/sir/stating_outcome/do cuments/Krathwohl.pdf.

[17] E. Godfrey and L. Parker, "Mapping the Cultural Landscopen in Engineering Education," Journal of Engineering Education, vol. 99, no. 1, pp. 522, Jan. 2010.

[18] C. F. Bunting and A. Cheville, "VECTOR: A Hands-On Approach That Makes Electromagnetics Relevant to Students," IEEE Transactions on Education, vol. 52, no. 3, pp. 350-359, Aug. 2009. 